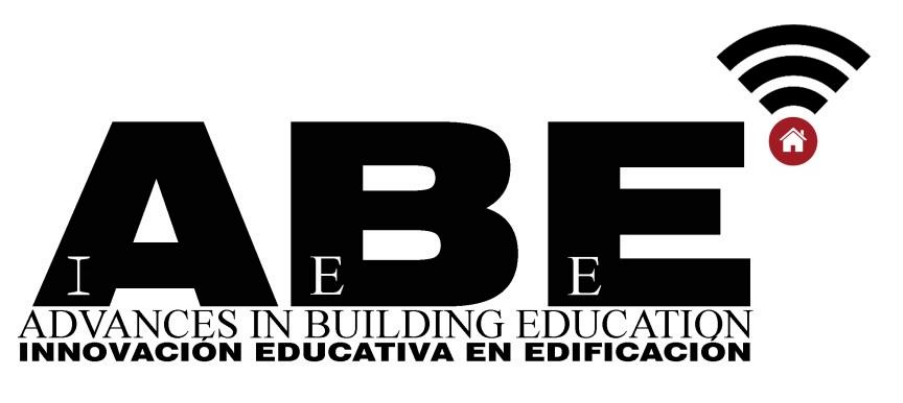

\title{
Influence of BIM-Based Teaching Methodology on the Spatial Abilities of Construction Engineering Students
}

\author{
Jesús Alberto Pulido Arcas ${ }^{1 *}$; Alejandro Martínez Rocamora ${ }^{2 *}$; Alejandro Folgar Erades ${ }^{3 *}$ \\ 1* University of the Bío-Bío. Collao, 1202. Concepción (Chile).jesus.a.pulido@gmail.com \\ ${ }^{2 *}$ ArDiTec Research Group. Department of Architectural Constructions II. IUACC. ETSIE. University of Seville. Av. Reina Mercedes, 4-a. \\ Seville (Spain). rocamora@us.es \\ $3^{*}$ Department of Building Structures and Geotechnical Engineering. Reina Mercedes, 12. University of Seville (Spain). afolgar@us.es
}

\section{Recibido: 21/10/2021 | Aceptado: 27/11/2021 | Fecha de publicación: 20/12/2021}

\section{DOI:10.20868/abe.2021.3.4732}

\section{HIGHLIGHTS}

- BIM models have not yet been fully used to nurture the different cognitive dimensions of AEC students.

- This study was set to clarify whether BIM can be an effective educational tool to improve the student's spatial abilities.

- An intensive training lasting for four weeks suggested that the spatial abilities of AEC students can be effectively improved with the use of native-BIM 3D models.

- The results of this study call for further research on the pedagogical values from shifting the AEC curricula to a fully BIM-based approach. 


\section{ABSTRACT}

Spatial visualization skills are considered essential for a variety of professional careers, especially those related with architecture, engineering, and construction (AEC). A number of studies have proven that these skills are progressively acquired by AEC students during their years in college, being necessary specific pedagogical approaches for this purpose. Other 3D native design software has been proved to exert a positive influence on the spatial abilities of students in several fields, such as fine arts or civil engineering. In the field of AEC, BIM software stands out as an appropriate tool for this purpose, as it supports 3D-native design. This study was conducted to clarify the influence that working with BIM models has on the spatial abilities of the students to visualize constructive components in 3D; it was hypothesized that the effect would be positive to some extent, as in similar disciplines. To that end, an experiment was conducted with 73 undergraduate students in construction engineering, who attended an intensive 4-week workshop where they had to work with BIM models. The improvement in their spatial abilities was measured by the Mental Rotation Test (MRT) and, besides, a satisfaction survey was conducted. The results indicate that MRT scores improved between $3.8 \%$ and $15.5 \%$ and that students felt highly satisfied with this pedagogical approach. These results aim to help in implementing BIM in the academic curricula to maximize the educational outcomes of the students while gathering their assessment of BIM-based teaching methodologies.

Keywords: Spatial Skills; Quantitative Analysis; Collaborative Learning; BIM; Chile.

\section{INTRODUCTION}

During the last decade, Building Information Modelling, commonly known as BIM, has impregnated not only professional practice in architecture and engineering, but also higher education. According to a survey conducted in 2015 across 39 countries in 6 continents BIM has remarkably penetrated in different geographical contexts, except for South America, being 3D coordination the most used feature anywhere [1]. This massive implementation of BIM in the construction industry has generated a demand for professionals proficient in this technology, pressing Higher Educational Institutions to adapt their academic curriculum for Architecture, Engineering and Construction (AEC) undergraduate programs.

With the exception of the Georgia Institute of Technology, which implemented BIM in the 90's, it was only after the early 2000's when BIM started to be introduced in the academic curricula [1], and after 2007 when it was consolidated across a remarkable number of institutions [2]. This recent implementation has impelled scholars and educators to consider how this new tool should be implemented, focusing on two main areas: How to integrate BIM as a core content in the academic curricula and how to develop specific competences of AEC students using BIM.

Regarding the first challenge, a coordination at three levels, teachers, curriculum and university, remains essential for some authors [3], outlining also that the transition from CAD to BIM, though being beneficial for students, would need one or two years to become effective. Particular case studies also support this view. The study conducted by $\mathrm{Hu}$ across 224 AEC students [4] to assess their grade of satisfaction with a shift from traditional drafting-based model pedagogy (DMP) to BIM-enabled pedagogy (BEP) indicated that students highly appreciated the new approach. It also outlines, based on a bibliographical revision, that the implementation of BIM has transited through 3 phases: AutoCAD to BIM transition (2006-2010), BIM integration in core courses as a stand-alone tool (2010-2014) and Crossdisciplinary collaboration (2014-2017). Other authors 
[5] have focused on the analysis of the performance of architecture students who received training in BIM, and created a set of recommendations to introduce BIM into the curriculum of AEC disciplines.

Given that BIM involves numerous specialties and areas, its ideal implementation in higher education programs requires full coordination amongst courses regarding both their schedules and educational agendas. This is difficult to achieve without a comprehensive curriculum-wide coordination $[3,6]$. According to some authors, integrating technology into the curriculum should not mean that computers help instructors teach the same old topics in the same old ways. On the contrary, instructors should take it as an opportunity to combine technology with emerging teaching and learning models to transform education. This transformation could aim, for instance, at implementing augmented or virtual reality as a learning tool [7], but on its way students should learn how to visualize, model and manage BIM projects.

Regarding the second challenge, BIM has also been considered a tool that can trigger the development of specific competences among AEC students. One of the most important seems to be collaboration and coordination [8] in the form of collaborative learning and project-based learning (PBL) which, in turn, can boost spatial visualization of the students.

Collaborative learning is a pedagogical method in which students working in groups can benefit from peer learning while achieving a common goal. The integration of BIM throughout the curriculum of these disciplines is considered essential as it replicates the workflow in the AEC industry [9]. Thus, BIM-based collaborative learning methods help bridge the gap between student learning and professional practice [10]. Hedges and Denzer [11] studied how BIM affects the learning environment of engineering students and concluded that BIM promotes group-based activities in classroom, where the students further specialize in specific areas of interest. This work methodology requires and supports interdisciplinary collaboration, and it is therefore suggested as a means to include interdisciplinarity in AEC degrees [12-14].

Researchers on education topics also highlight computer technologies as an important component to support project-based learning (PBL) [15]. Specifically, BIM allows for a decrease in the time to carry out labor-intensive tasks, such as quantity surveying and scheduling [16]. Mathews [10] explored the benefits of BIM-based collaborative learning through a studio-based design and construction project where a professional architect partnered with six architectural technology students. PBL showed the potential to prepare and equip students with a problem-solving set of skills based on collaborative work.

Other major challenge is how to develop spatial abilities, i.e. change from $2 D$ to native-3D design, which implies a completely new way of teaching. Denzer \& Hedges [17] mention that "BIM prompt students to think about architecture, structure and mechanical systems in an integrated manner, and to consider issues of materiality and construction at an early stage of the design (compared to traditional 2D design)", a claim that has been backed up by numerous studies.

Nguyen \& Nguyen [18] found out that the application of BIM tools in training courses not only equips students with modelling skills, but also facilitates other subjects through its vivid simulation and illustration of buildings. Some of the lacking skills identified were the complexity of the interface, three-dimensional space cognition, and teamwork skills. Moreover, it has been found that the application of BIM can improve specific learning activities [19]. For example, there are educational experiences where BIM was used to enhance student learning in structural concrete design courses 
through clearer 3D visualization, which produced improvements of $4.7 \%$ to $10.1 \%$ in the student's performance [20].

Not only the performance and the abilities of students, but also their self-assessment of their learning seems to improve. Through his experience using BIM as a pedagogical tool for teaching HVAC systems to architecture students, Mokhtar [21] identified visualization issues associated to the relationship between HVAC components and other building elements; the students' feedback reported that $90 \%$ to $96 \%$ of them had acquired a better understanding of HVAC systems after the course. Suwal and Singh [22] assessed the students' sentiments about the use of a BIM learning platform in a construction project management course. As a result of their novel teaching strategy, the students scored better and provided positive feedback. Sánchez et al. [23] evaluated the students' perceptions of the advantages and difficulties of incorporating BIM as part of the degree in industrial engineering, delivering very positive results in terms of self-assessment and skill acquisition.

Most of the aforementioned studies were conducted in countries where BIM standards such as the ISO 19650 and 29481 series [24,25] are widely implemented. At this point is where Chile stands out as a compelling case-study, as the implementation of BIM has recently experienced significant advances. The national institute for standardization (INN), in close coordination with the International Standard Organization (ISO), established a national committee to adopt these international standards. In addition, this committee closely collaborates with PlanBIM [26], a national organization in charge of elaborating standardized documents that ease the transition of the AEC sector to BIM. As a result of analyzing the aforementioned international standards, among others, PlanBIM published in 2019 the BIM standard for public projects, which regulates the tendering processes of BIM projects [27]. This standard will become mandatory for public and private projects in 2020 and 2025, respectively.

This recent boost of BIM in Chile has promoted the implementation of BIM courses at universities across the country; as per $2017,35 \%$ of the institutions of higher education in AEC have implemented BIM [28] using different pedagogical approaches. BIM is mainly implemented in degrees in construction engineering (69\%), architecture (67\%) and civil engineering (50\%). The University where this study was conducted has opted to include BIM as specialized lessons in certain courses, in accordance with the approach used in other programs worldwide [29]. In brief, the degree in construction engineering at this institution lasts for 10 semesters and BIM is introduced as a content in certain courses from the $5^{\text {th }}$ semester, such as project budgeting, constructive detailing and MEP systems.

This state of affairs suggests that, despite the pedagogical benefits of BIM have been profusely investigated, there is still a research gap regarding how it can boost specific skills of AEC students, specifically their spatial abilities. This remains particularly important in the Chilean context, where, in comparison with other countries, there is still scarce evidence on the potential benefits of this methodology.

The spatial visualization abilities of a person have been a research field of interest for a long time, and are usually defined as the ability to mentally manipulate, rotate, twist or invert bi-dimensional representations of three-dimensional objects [30]. This ability is a cognitive skill vital to many disciplines, especially those requiring work with graphical images [31]. Glick et al. [32] stated that the ability to visualize construction plans, sections and details of construction components, create estimates and schedules are critical functions of construction managers that strong visualization skills help making easier; however, there is uncertainty about whether 


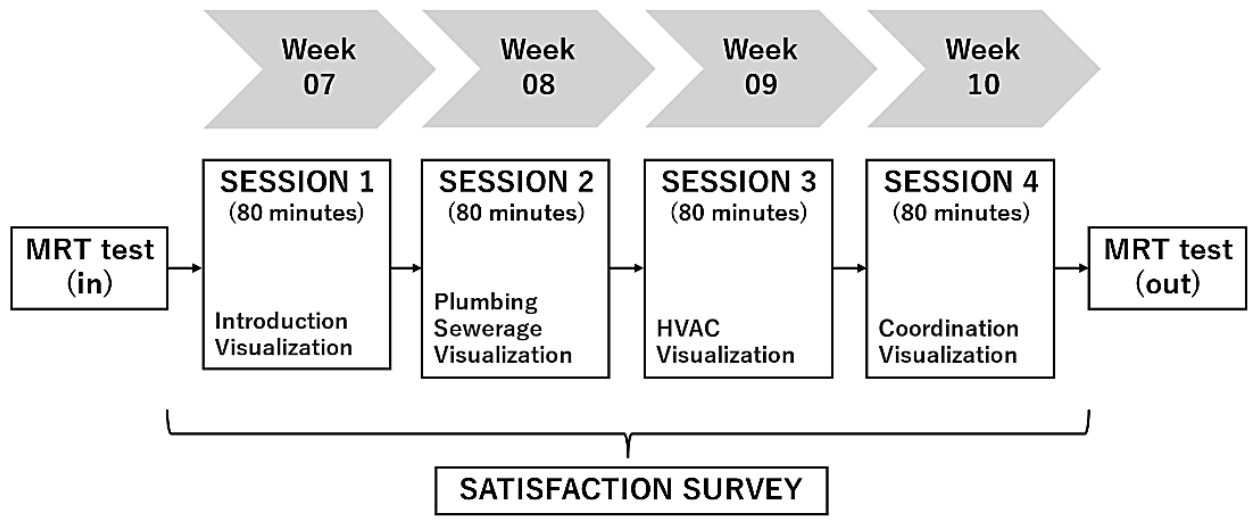

Figure 1. Activities of the experiment (Source: The authors)

spatial cognition is something people have or something they learn. For example, Williams et al. [33] conducted an experiment with sophomore engineering students, in which they took four spatial ability tests, including the Paper Folding Test, the Vandenberg-Kuse Mental Rotation Test, the ShepardMetzler Mental Rotation Test, and the Spatial Imagery Ability Test. Their results indicated that spatial ability had no relationship to the selection of their future discipline, since sophomore students showed a baseline equality in their results. However, it was expected that students would develop different cognitive skills over time due to differences in curricula. According to Sorby and Baartmans [34], individuals acquire spatial skills in three stages from childhood starting with how close the objects are to one another. Later, these abilities evolve to how an object will look like from different perspectives, and finally to combine these abilities with the concept of measurement.

Although there is extensive evidence that BIM can improve on some of the student's competences, there is comparatively few research about the outcomes that BIM might have on their spatial cognitive abilities. This remains crucial because there is still a gap between adoption of BIM in the design and the construction phase, where information still heavily relies on paper; this means that professionals have to resort to their spatial cognition to interpret it.
Indeed, and according to a recent survey by PlanBIM, this gap is present in Chile: Across BIM users, $64,1 \%$ of them declare that they use it to coordinate different building systems or visualize the design as a whole, but few of them use it to analyze elements in $3 \mathrm{D}(32,8 \%)$ or to inspect works onsite $(26,6 \%)[28]$.

In fields related to construction engineering, some studies have been conducted to assess the influence of other digital design tools on the spatial abilities of the students. SketchUp ${ }^{\circledR}$ has been used by some other instructors to help improving the spatial visualization of the students of Vocational schools; this tool was implemented in a specific course to help them to visualize embankments in $3 D$ and topographic profiles. Not only their spatial visualization was improved, but the students also showed a positive attitude towards this technology, being especially keen on the usability and the attractiveness of such tools [35]. Other study assessed the improvement of the spatial abilities of undergraduate students of fine arts after working with 3D models in SketchUp ${ }^{\circledR}$. The students took a Mental Rotation Test (MRT) before and after an intensive workshop and their scores remarkably improved and, what is more, $95 \%$ of the participants indicated that interactive exercises with SketchUp ${ }^{\circledR}$ were beneficial for the development of their spatial abilities [36]. Martín-Dorta et al. [37] obtained substantial improvement in the spatial abilities of civil 
engineering students after using SketchUp ${ }^{\circledR}$. The activities lasted for 3 weeks, including 12 hours of tutoring in a course based on exercises with three levels of difficulty. First, the students had to build a 3D model based on a small object. Second, they had to generate a 3D model of a piece from its axonometric projections. Finally, they built 3D models of parts from their orthographic views. The study concluded the activities had a positive impact on the spatial abilities, which were measured using both MRT and DAT:SR tests.

These studies show that the use of 3D digital design tools can be beneficial for those students whose field of specialty encompasses spatial skills as a competence. Taking them as a basis, it was deemed necessary to assess if this relation holds true in the case of undergraduate AEC students using BIM. This study was considered necessary because BIM has some peculiarities. In contrast with the software used in previous studies, it is primarily a tool for organizing information in buildings; however, it allows for interactive $3 \mathrm{D}$ visualization in the same fashion as other software, although it is specifically aimed at design in Architecture and Building Engineering.

This study aims at filling this gap with an educational experiment that intends to clarify two main questions: Does working with BIM, using collaborative models improve the spatial abilities of the students to visualize constructive components in 3D? and, will students be satisfied with the new pedagogical approach? For that purpose, an experiment was designed based on similar research conducted in other fields, but adapting it to the schedule of two courses of the degree in Construction Engineering: Sanitary and HVAC systems.

According to similar studies, it was hypothesized that BIM will allow for some improvement in their spatial abilities and the students will feel satisfied with the shift in the teaching methodology [38]. However, since studies in this specific field are scarce, it is somehow difficult to foresee particular figures regarding the improvement. It is expected that the findings from this study will add to the understanding of the influence of BIM in certain AEC courses and the educational approach that best fits students' needs and preferences.

\section{MATHERIALS AND METHODS}

\subsection{Participants and educational background}

106 students of the undergraduate program in construction engineering of the University of the BioBio took part in the activity. They were enrolled in two courses that are taught during the $5^{\text {th }}$ and $7^{\text {th }}$ semester. Therefore, all participants were between 20-22 years old. The first course deals with plumbing, sewer and gas systems and the second one with HVAC (heating, ventilation and air-conditioning) systems. Both courses are strongly oriented towards Project Based Learning (PBL) and students work in groups of 3-4 people to design such systems using a case-study building proposed by the instructor. They are graded with a final report that includes the design, calculations and blueprints of the whole systems for the proposed building.

\subsection{Experimental design}

A course in this degree last for 18 weeks (1 semester). Every week the students attend an 80 -minute lecture with the theoretical contents and an 80-minute practical class where they work on their group project. In order to implement these activities into the normal 
(a)

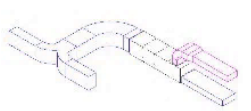

(b)

(c)

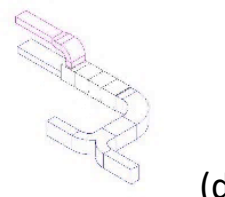

(d)

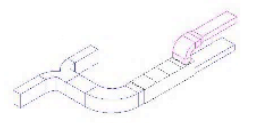

(e)

Figure 2. Sample question of the administered MRT. (a) Original image, (b) and (c) two correct options and (d) and (e) two incorrect options.

(Source: The authors)

syllabus of the course, some adaptations had to be made. The activities were implemented during the practical sessions of weeks $7,8,9$ and 10, that is, 4 sessions of 80 minutes each; they took place in the computer lab of the School of Construction Engineering, which is equipped with 60 PC's with BIM software (Autodesk Revit). All computers are connected to the internal server of the lab, so teamwork across all participants is possible.

This project was financed by a program that aims at promoting pedagogical innovation in undergraduate programs. The primary objective of the project was to explore the implementation of BIM into the degree of Construction Engineering, mainly focusing on the sanitary and HVAC systems courses; it featured the collaboration of an invited instructor, a professional BIM consultant who came from Spain for 4 weeks for this purpose. During all sessions, both the invited teacher as well as the regular instructors were present in the computer lab. All the sessions were given in Spanish, the mother language of both the invited teacher and the students.
The experiment consisted of 3 main activities (Fig. 1): The MRT, which was administered before and after the workshop; a workshop, which consisted on the aforementioned 4 weekly practical sessions; and a satisfaction survey.

\subsection{Mental Rotation Test (MRT)}

The spatial abilities of the students were measured using a modified version of the Vandenberg-Kuse Mental Rotation Test (MRT), which was administered before and after the 4 sessions; these tests are widely standardized and measure the spatial ability of participants; in the Vandenberg-Kuse modality they have to compare 3D objects and state if they are the same or a mirror image of the original one.

In this case, the participants had to compare 3D isometric perspectives of sanitary and HVAC installations. The first question of the test was solved as an example and depicted a 3D figure composed by cubes. After this, students would proceed to the actual test, which consisted on 8 questions and lasted for 45 minutes: The first 2 questions included 3D axonometric views of figures and the remaining 6, 3D views of different installations. Each question depicted the original image and 4 copies, among which 2 were correct (Fig. 2); this information was disclosed to the students.

The test was administered using Moodle, so that some parameters could be controlled. The order of the questions was the same for all students, but answers were shuffled in each question so that students could not copy from each other. Besides, as the same test was administered before and after the workshop, two precautions were taken to prevent students from remembering their previous answers: first, the final test was administered 5 weeks after the previous one and the students were not aware that the test would be repeated at the end of the experiment; second, in the first test students were asked to identify the correct answers, whereas in the 
final test they had to choose the incorrect answers. They were also informed that the results from those tests would not have an influence on the final grade of the course.

\subsection{Workshops}

The second activity consisted on a workshop with 4 sessions of 80 minutes each. Students worked on different activities on how to design and visualize sanitary, gas and HVAC installations. The first session introduced the students to the main concepts about design and visualization of MEP systems in BIM; the three remaining sessions were dedicated to each specific system (Fig. 1).

Each session was organized as follows: theoretical and practical explanations pertaining to the design and visualization of installations were given for the first 30-40 minutes and students had to work individually, reproducing in their computers the tasks executed by the instructor. After that, a central model of a case-study, in this case a hotel, was uploaded to the central server; students were divided into groups of 3-4 people and each group was assigned to specific tasks according to different roles: some groups acted as designers, others as contractors and others as project managers, and all of them worked collaboratively to come to an agreement about the best possible design. Teams worked exclusively on their computers without the aid of any blueprints.

In such way two main competences were intended to be developed during these workshops: spatial visualization and collaborative learning. First, students had to work with native 3D models from the beginning, avoiding the gap between 2D visualization (blueprints) and 3D visualization. Conversely, they worked intensively using 3D models and frequently had to resort to the 3D visualization tools available in BIM software: Isometric perspectives, free navigation across the 3D model and 3D sections, among many others. Second, BIM allowed for collaborative learning and feedback across all participants; the central model was shared between all teams, so that they were continuously spotting clashes between different systems and receiving feedback from their peers.

\subsection{Satisfaction survey}

After the workshop a satisfaction survey was conducted across the students. This survey was based on a standard model designed by the Department of Pedagogical and Technological Development of the University where the study was conducted; it is aimed at assessing the satisfaction of students with the methodology of teaching-learning activities. The students had to answer 11 questions, rating each aspect of the activities from 1 (Strongly disagree) to 4 (Strongly agree), according to Likert-type scale; the last question, related to the grading system, was removed since this activity had no influence on their final grades, and substituted by a text box where they could express their concerns, suggestions or opinions about the activity.

\subsection{Experiment metrics and data analysis. MRT} tests.

Despite the initial sample size was 106 students, the final number of participants was smaller since some factors had to be considered. First, as some students were absent whether at the day of the initial or the final MRT, comparison between the initial and final scores was only possible for students present at both times. In such way, 106 students took the initial test, 85 the final test and, combining both sets of data, 84 students took both tests and were available for comparison.

Second, some answers were discarded after a careful analysis of the results available from the Moodle platform. The score of some tests was zero and all the answers were left blank, which meant that the 
students just opened the test and waited until time was over, or alternatively they just went through the test without answering any question. 3 answers were discarded, with a recorded time of 47 minutes and 52 seconds, 47 minutes and 50 second, and 36 seconds. Additionally, some other answers indicated anomalous behaviors, such as the final test taking less than half the time of the initial test, with the second half of the questionnaire registering wrong answers, which could mean that those students wanted to finish the test quickly and did not analyze each question appropriately. That left 72 valid answers (67.9\% of the original sample size), which were used for the statistical analysis that was done in two steps: First, box and whiskers plots were used to unveil the major trends, and secondly, inference tests were carried out to clarify deeper relations that might be present.

In order to apply inference to the observations from the MRT, these had to be studied as two paired sets of observations with two results from each student, that is, the initial and final test scores. Therefore, it was first necessary to calculate the difference between these two scores for each student and study the resulting variable (Sdiff). This difference was calculated as the final test score minus the initial test score, since the study aimed to detect improvements in the students' abilities.

The methods for inference for two paired variables require the observations to be independent from each other, and to follow a nearly normal distribution. The distribution of the Sdiff variable inherently complies with the first requirement, since each student took their own tests. Regarding the normality requirement, a workflow consisting on an initial exploratory data analysis (EDA) and a series of normality tests was performed. For the EDA, the distribution was studied through a frequency histogram, complemented with a density distribution and a quantile-quantile (Q-Q) plot.
In a second step, the distribution was subjected to a triple normality test. First, the Kolmogorov-Smirnov one-sample test; second, the Anderson-Darling test; third, the Shapiro-Wilk test. This was decided because each test has pros and cons regarding data analysis and accuracy [39], so comparing the results from the three techniques would allow for a deeper analysis of the data.

Finally, a two-step inference was performed on the Sdiff dataset. First, a hypothesis test was carried out to demonstrate that the students receiving the aforementioned courses improved their spatial visualization skills (Sdiff):

HO: $\mu=0$ (the score obtained in the MRT does not vary for the population)

HA: $\mu>0$ (the score obtained in the MRT improves for the population)

Secondly, a new inference test was performed to determine a $95 \%$ confidence interval of the improvement in the MRT scores of the students (Sdiff) based on the mean statistic. This test has two main aims: to confirm that the resulting interval does not include the null value, and to discover the magnitude of the improvement in relation to the maximum score of the MRTs.

\subsection{Experiment metrics and data analysis. Satisfaction survey}

As the satisfaction survey was voluntary and anonymous, 69 answers were collected, which represented around $65 \%$ of the original sample size and $95.8 \%$ of the students considered for the analysis of the MRT. The survey was anonymous and individual names were not registered, so it cannot be assured that those 69 respondents actually took both MRT tests. That represents, in some way, a flaw in the methodology because it would not be possible to compare the degree of satisfaction of each individual with the improvement in the spatial abilities. 
However, the survey was kept anonymous because the authors considered more important that the students could express their opinion freely, disregarding the outcomes of the activities.

\section{RESULTS}

\subsection{MRT test scores}

Table 1. Summary of statistical analysis for the MRTs.

\begin{tabular}{|c|c|c|c|c|}
\hline Statistics & $\begin{array}{c}\text { Initial } \\
\text { test }\end{array}$ & $\begin{array}{c}\text { Final } \\
\text { test }\end{array}$ & $\begin{array}{c}\text { Difference } \\
\left(\mathbf{S}_{\text {diff }}\right)\end{array}$ & $\begin{array}{c}\text { Hypothetical } \\
\text { distribution }\end{array}$ \\
\hline $\begin{array}{c}\text { Number of } \\
\text { students }\end{array}$ & 106 & 85 & 72 & - \\
\hline Mean & 3.943 & 4.176 & 0.6743 & 0.6743 \\
\hline $\begin{array}{c}\text { Standard } \\
\text { deviation }\end{array}$ & 1.547 & 2.143 & 1.7358 & 1.7237 \\
\hline $\begin{array}{c}\text { K-S test } \\
\text { score (p- } \\
\text { value) }\end{array}$ & - & - & $0.0883(0.6283)$ \\
\hline $\begin{array}{c}\text { A-D test } \\
\text { score (p- } \\
\text { value) }\end{array}$ & - & - & $0.5183(0.7277)$ \\
\hline $\begin{array}{c}\text { S-W test } \\
\text { score (p- } \\
\text { value) }\end{array}$ & - & - & $0.9752(0.1663)$ \\
\hline $\begin{array}{c}\text { t-Test score } \\
\text { (p-value) }\end{array}$ & - & - & $\begin{array}{c}3.2963 \\
(0.0008)\end{array}$ & - \\
\hline $\begin{array}{c}\text { Confidence } \\
\text { interval } \\
\text { (95\%) }\end{array}$ & - & - & $\begin{array}{c}(0.2664, \\
1.0822)\end{array}$ & - \\
\hline
\end{tabular}

MRT test scores were first measured based on two parameters: scores and required time to solve the test. Regarding the scores, they were measured using the Chilean scoring scale for higher education, which ranges from 0 to 7 , being 4 the minimum required to pass a test. Average scores showed some improvement, both in the average and the median values (Fig 3.a). There was also a remarkable improvement in the time taken to solve the test; both average and median time were reduced around 3 minutes (Fig 3.b). However, a particular tendency was observed for the scores, where the distribution became more disperse, which means that, despite some students improved their performance, some of them seemed to be doing worse or best in the final test. As this data seemed still not conclusive, the exploratory analysis was conducted to clarify if those activities improved the spatial ability of the students.

The initial exploratory data analysis described in Section 2.6 (Fig 4.a) was conducted, and it was observed that the studied dataset seems symmetric and could follow a nearly normal distribution, despite it appears to be slightly left-skewed (Fig 4.b). The

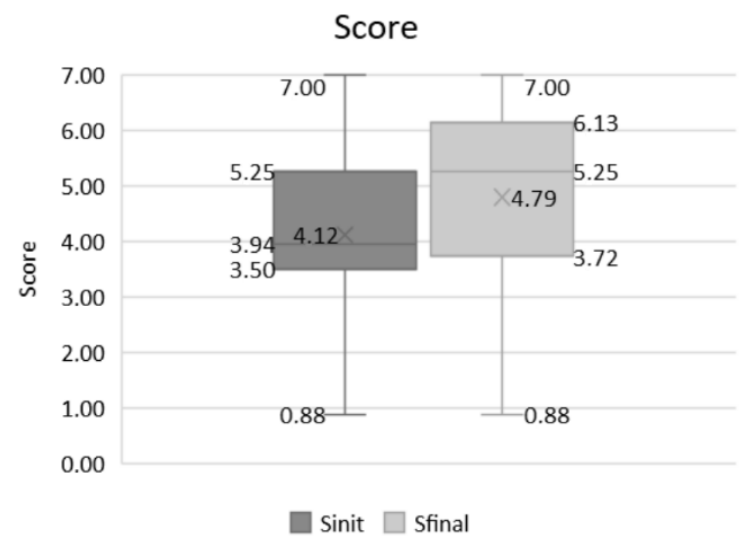

(a)

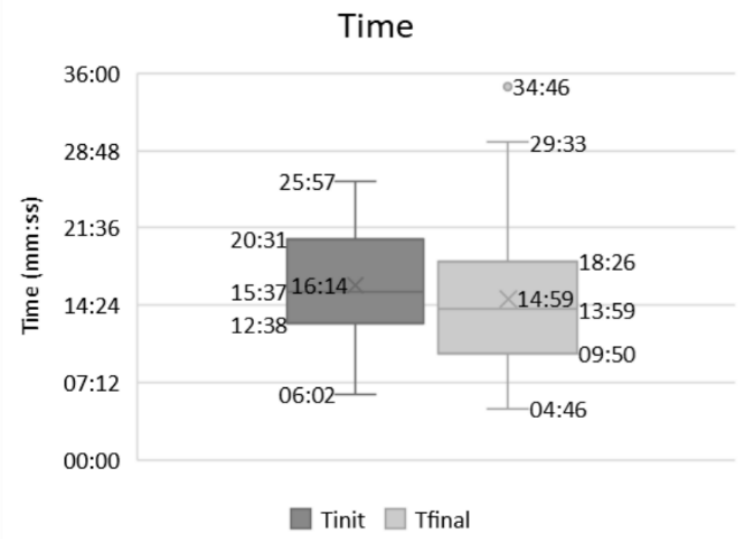

(b)

Figure 3. (a) Scores of the MRT test and (b) time for solving them. 

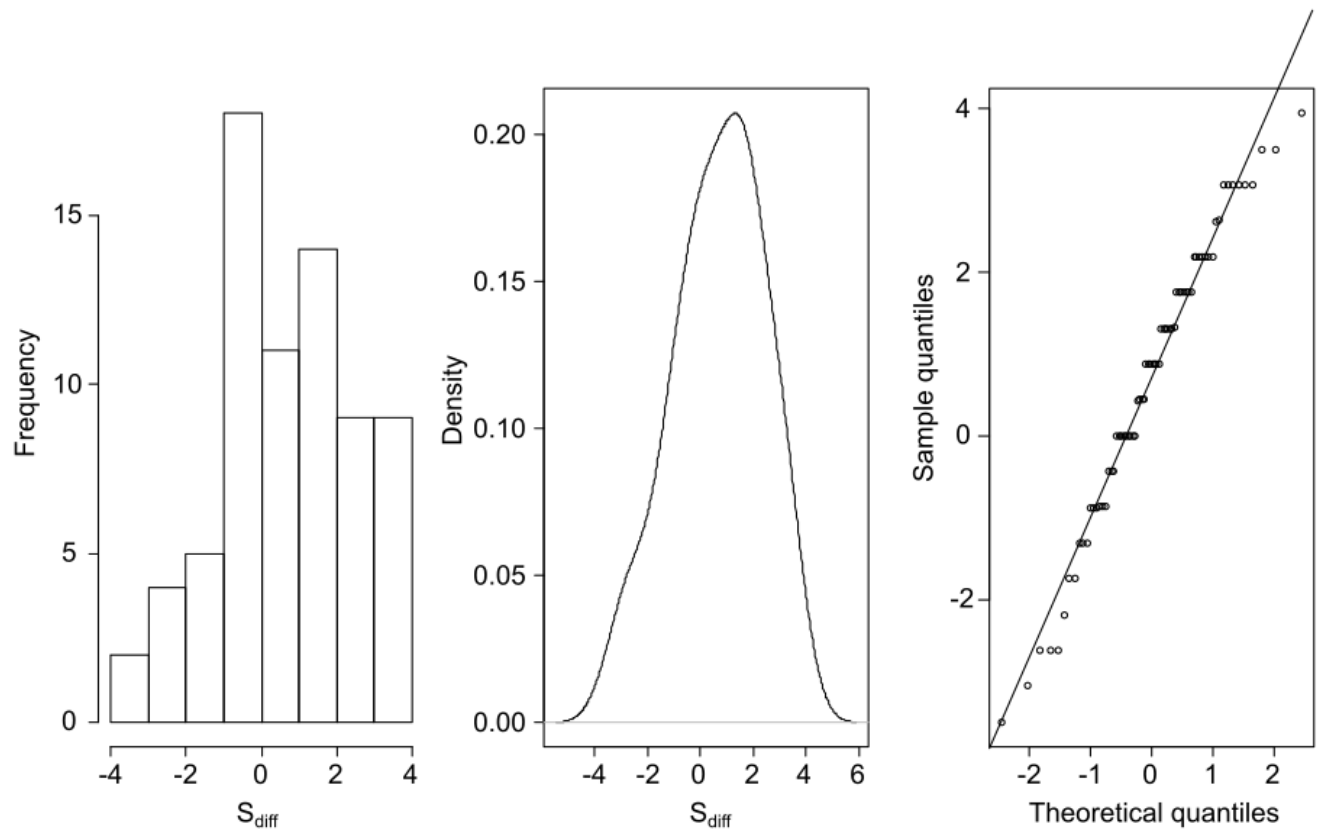

Figure 4. Exploratory data analysis applied to the Sdiff distribution. From left- to righthand side: frequency histogram, density distribution, and Q-Q plot.

1. I feel satisfied with my capacity of relating concepts with real-life situations

2. I feel satisfied with my understanding of the contents

3. I feel satisfied with my motivation towards the proposed activities

4. I feel satisfied with my learning outcomes

5. I feel satisfied with the assistance from the instructor

6. I feel satisfied with my degree of participation in these activities

7. I feel satisfied with my dedication to these activities

8. I feel satisfied with the timing of the activities

9. I feel satisfied with the duration of the activities

10. I feel satisfied with the activities

11. I feel satisfied with the methodology of the activities

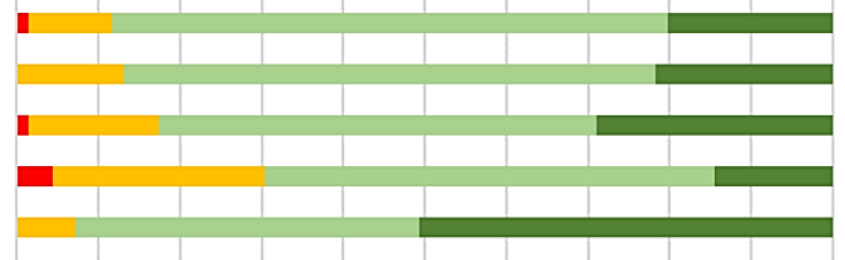

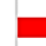

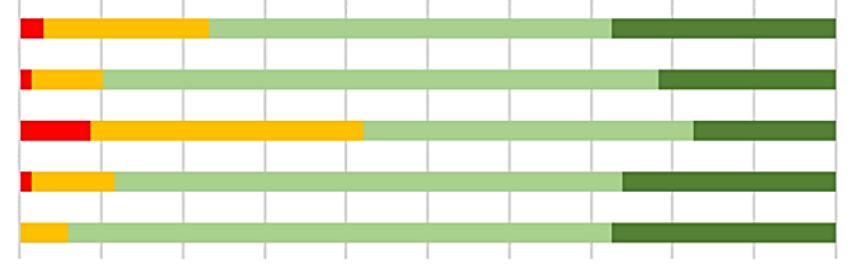

$\begin{array}{lllllllllll}0 \% & 10 \% & 20 \% & 30 \% & 40 \% & 50 \% & 60 \% & 70 \% & 80 \% & 90 \% & 100 \%\end{array}$

@ Strongly disagree $\square$ Disagree $\square$ Agree $\square$ Strongly agree

Figure 5. Results from the satisfaction survey.

Q-Q plot in the right-hand side shows an apparently discrete distribution caused by the scoring system of the MRT questions (Fig 4.c); in each question 2 options were correct and 2 incorrect: 0.44 points were given for each correct answer, that is, 0.88 if both correct answers were chosen; no points were deducted if an incorrect answer was chosen.
Subsequently, the parameters of the hypothetical distribution (normal distribution) for the observations were estimated, obtaining a mean of 0.6743 and a standard deviation of 1.7237. These parameters were then used for a triple goodness-offit to normal test based on the one-sample Kolmogorov-Smirnov (K-S), Anderson-Darling (A-D), and Shapiro-Wilk (S-W) tests, which delivered $\mathrm{p}$ values of $0.6283,0.7277$ and 0.1663 for the $S_{\text {diff }}$ 
distribution, respectively (Table 1 ). These results indicate, with a $95 \%$ confidence level, that the distribution can be considered nearly normal.

Once the requirements for inference have been checked, the hypothesis test described in Section 2.6 was carried out to prove, with a $95 \%$ confidence level, that students receiving this course improved their spatial abilities $\left(S_{\text {diff }}>0\right.$ ) (Table 1$)$, which allows rejecting the null hypothesis and assuming that the proposed activities produced a positive variation in the MRT score.

In order to determine the improvement of the students' scores in the MRT, an extra inference analysis was carried out on the $S_{\text {diff }}$ distribution in order to establish a $95 \%$ confidence interval of this variable. This analysis delivered a confidence interval between 0.2664 and 1.0822 , representing a $3.8 \%$ to $15.5 \%$ improvement in the spatial abilities demonstrated by the students in the MRT.

\subsection{Satisfaction survey}

69 students answered this survey and, as said before, it was not possible to determine with total accuracy if all of them took part in the activities. However, it could be said that there is a high probability that all of those answering the survey actually participated in the activities, based on the following data: First, 69 answers represent $95.8 \%$ of those participating in the activities, which suggest a high degree of coincidence. Second, only 9 students left the space for comments blank, and the rest (60) commented on aspects of the activities; this suggest that, amongst those answering the survey, at least $87 \%$ were present in the activities and took the MRTs. Therefore, it can be said with an acceptable degree of confidence that $87-95 \%$ of the students who answered the survey did participate in the activity and took the MRTs.

As can be seen in Figure 5, in general, the students seemed satisfied with the activities during those 4 weeks. For all questions, students that "agreed" or "strongly agreed" with the statements tallied more than $70 \%$ (in question 4 the exact percentage was $69.6 \%)$; there was one exception in question 9, where this percentage was only $58 \%$. The students seemed to be particularly satisfied with the assistance received from the invited teacher, the schedule of the activities and the organization in general. On the other hand, the lowest degree of satisfaction corresponded to the duration of the activities.

In order to find an explanation to this relatively low degree of satisfaction with the learning outcomes and the duration of the activities, the individual comments from the respondents in question 12 were screened and three trends were found: 32 comments expressed concerns about the short duration of the activities, 21 pointed out some aspect of the methodological approach and 8 criticized the student/teacher ratio. Some examples are shown below.

It would be a good idea to carry out these activities for a longer time, not for one month, but during the whole semester, so we can become familiarized with this software.

The instructor seemed overwhelmed sometimes. There were too many students and he was alone. It would be a good idea to bring a teaching assistant to answer questions and work together with the instructor.

The activity should have included a project that we were already familiar with.

\subsection{Discussion of results}

The results of this experiment suggest that working with 3D-native BIM models can have a positive impact on the spatial abilities of undergraduate AEC students. Their scores improved, in average, around $27 \%$, and the time taken to solve the test decreased around $7.7 \%$. The inference test also supports these results, but delivers more discrete figures, around 
3.8\% - 15.5\%. Therefore, it seems evident that after the proposed activities students can better interpret three-dimensional information in less time, which would prove the initial hypothesis of the study.

It is noteworthy that results from similar research support these conclusions, although the number of existing studies is scarce because measuring the effect of 3D-native BIM models on the spatial skills of the students appears to be a novel field of study. The discussion focuses on two aspects: the improvement in the spatial abilities and the teaching time in relation with the pedagogical approach.

Research conducted in related fields, such as fine arts, suggested that the use of non-specialized 3D software would increase the MRT scores around 44\% [36]; however, no information was provided about the time taken to solve the test. Similar results can be found in studies conducted in other contexts. Male workers of the electronic industry without formal training on CAD systems showed a significant improvement in their spatial abilities after working with computer generated models for 4 weeks [39]. Despite this study might be a bit outdated, which means that there could be more technical limitations regarding the available technology for 3D visualization, it is remarkable how the average score in the test of 3D-shape visualization improved by $40 \%$. Also, for engineering students this tendency remains valid. An improvement of around $27 \%$ in the MRT scores was found after working with multimedia software for 2 hours each week during one semester [40].

Another point to discuss is the duration of the activities, which might bear some relation with their outcomes. The workshops in this experiment lasted for 5 hours and 20 minutes, which is similar to the study by De La Torre Cantero et al. [36], which comprised 3 sessions of 120 minutes each (6 hours in total). The study by Gerson et. al [40] showed a different approach, distributing the sessions over a whole semester. The improvement in the spatial abilities seems to be unrelated with the teaching time and the schedule of the activities. Both an intensive workshop lasting for some weeks or an extended training for the whole semester seem to deliver good outcomes.

Therefore, regarding the educational outcomes and the methodological approach, it seems that the present study is in line with similar research; however, some additional questions remain open. First, it may be suggested that the effect of 3D software can be boosted if used together with real 3D pieces, as in the study by De La Torre Cantero et al. [36]. Second, it should be considered that previous research was using non-specialized 3D visualization software, whereas in this case BIM was used; despite having a strong visual component, it is primarily a tool for organizing information, not for 3D visualization. In such way, conclusions suggest that BIM can also serve for this purpose. Third, additional studies do not provide information about the time taken to solve the test, which also remains important; this research points out that students are not only better, but also faster in interpreting 3D information correctly. Last, it is arguable how long these activities should last to see a significant effect: 4 weeks seemed to be sufficient in this case, but it could be the case that a prolonged training, lasting all semester, could produce greater improvement in the students' spatial abilities.

This last concern connects with the most significant results from the satisfaction survey. Indeed, the students seemed satisfied with the activities as a whole, in concordance with other research [40]. However, around $40 \%$ of them seemed unsatisfied with their duration; generally, they claimed for longer activities and more specialized instructors, which suggests that they are asking for a BEP that lasts an entire semester, in line with the pedagogical approach by Hu [4]. Both would imply a modification of the whole curricula, which agrees with the 
pedagogical approach presented by Berwald [3] and Nushi [6].

\section{CONCLUSIONS}

In this study, the improvement in the spatial abilities of students and their satisfaction after applying a new learning method based on intensive sessions of subject-related BIM modelling with an expert consultant were analyzed. According to the results, it can be said that the hypothesis was validated. The spatial abilities of the students were improved, and they showed a remarkable degree of satisfaction and, what is more, showed a constructive critic approach towards the implementation of these activities.

However, this study faced several limitations. First, this research was financed by a project with a limited amount of resources, which only allowed the external instructor to work with the students for 4 weeks. Besides, a single instructor was available for 4 groups, being each one composed by approximately 25 students; according to the satisfaction survey this ratio seems insufficient since collaborative learning demanded a great amount of time and effort from the instructor. These drawbacks call for a study in a larger scale, lasting for one semester and having at least one instructor and one teaching assistant for each group in order to maximize the outcomes. Despite the students had previous instruction in spatial geometry and CAD software, the great majority of them had no previous BIM knowledge which, at some points, hindered the progress of the activity. Again, this could be solved by integrating BIM in the curricula of the Construction Engineering degree from the first semester, including specific knowledge related to each subject as suggested by Ghosh [9].

Second, the activities were voluntary as, at that time, BIM was not officially part of the course syllabus thus could not be included as an evaluation criterion. For that reason, dropouts were registered, mainly at the end of the activities and accounting for $32 \%$ of the initial sample. This drawback can mostly be associated with students lacking interest in BIMrelated activities, and this might have an influence on the final result, as those participants lacking motivation were not registered in the tests. That drawback had an influence on the sample size. Similar studies featured 60 [39], 20 [40] and, more recently, 40 participants [36]; despite the present study included a bigger sample size, it would be desirable to replicate it in the future, paying special attention to dropouts.

Altogether, the findings from this research suggest that students can improve their spatial abilities by using BIM in their instruction, and that they can in turn better interpret graphical information of MEP systems. Collaborative learning can help in the implementation of this new pedagogical approach, delivering high degrees of satisfaction. There is still a gap in Chile between the usage of BIM in the design and the construction phase [28], which means that paper-based information is still mainstream in the construction site. In such way, this study will help in devising new pedagogical approaches, adapted to the students' needs and preferences, that will improve their spatial abilities and help them to interpret blueprints in a faster and more accurate way.

\section{ACKNOWLEDGEMENTS}

This research has been undertaken as part of the project "Strengthening of the implementation of the BIM methodology in undergraduate and graduate programs of the University of the Bío-Bío by the invitation of an international expert", which has been funded by the program "Financial support for the development of academic curricula" (FAPE by its Spanish acronym) from the University of the Bio-Bio. The authors would also like to thank the Research Group in Integrated Building Design and Management at the Universidad del Bío-Bío. for its support in the successful completion of this project. 


\section{REFERENCES}

[1] W. Jung, G. Lee, The Status of BIM Adoption on Six Continents, Int. J. Civil, Struct. Constr. Archit. Eng. (2015). doi:https://doi.org/10.5281/zenodo.1100430.

[2] M.B. Barison, E.T. Santos, BIM teaching strategies: An overview of the current approaches, in: EG-ICE 2010 - 17th Int. Work. Intell. Comput. Eng., 2019.

[3] S. Berwald, From CAD to BIM: The experience of architectural education with building information modeling, Proc. AEI 2008 Conf. - AEI 2008 Build. Integr. Solut. 328 (2008). doi:10.1061/41002(328)8.

[4] M. Hu, BIM-Enabled Pedagogy Approach: Using BIM as an Instructional Tool in Technology Courses, J. Prof. Issues Eng. Educ. Pract. (2019). doi:10.1061/(ASCE)El.1943-5541.0000398.

[5] J. Ferrándiz, F. Del Ama Gonzalo, M. SanchezSepulveda, D. Fonseca, Introducing a new ict tool in an active learning environment course: Performance consequences depending on the introduction design, Int. J. Eng. Educ. 35 (2019) 360-371.

[6] V. Nushi, A. Basha-Jakupi, The integration of BIM in education: A literature review and comparative context, Glob. J. Eng. Educ. 19 (2017) 273-278.

[7] A.H. Behzadan, A. Iqbal, V.R. Kamat, A collaborative augmented reality based modeling environment for construction engineering and management education, in: Proc. - Winter Simul. Conf., 2011: pp. 3568-3576. doi:10.1109/WSC.2011.6148051.

[8] M. Yakami, V. Singh, S. Suwal, What do students and professionals think of BIM competence?, in: IFIP Adv. Inf. Commun. Technol., 2017. doi:10.1007/978-3-319-72905-3_32.
[9] A. Ghosh, Virtual Construction + Collaboration Lab: Setting a new paradigm for BIM education, in: ASEE Annu. Conf. Expo. Conf. Proc., San Antonio, Texas, 2012: pp. 25.1459.1-25.1459.12.

[10] M. Mathews, BIM collaboration in student architectural technologist learning, J. Eng. Des. Technol. 11 (2013) 190-206. doi:10.1108/JEDT-102011-0067.

[11] K.E. Hedges, A.S. Denzer, How a collaborative architecture influences structural engineering education, in: 2008 Struct. Congr., Reston, VA, 2008. doi:10.1061/41016(314)147.

[12] M.J. Casey, Work in progress: How building informational modeling may unify IT in the civil engineering curriculum, in: 38th Annu. Front. Educ. Conf., Saratoga Springs, NY, USA, 2008. doi:10.1109/FIE.2008.4720644.

[13] F.J. Sabongi, The integration of BIM in the undergraduate curriculum: an analysis of undergraduate courses, in: 45th Annu. Conf. ASC, 2009. doi:10.1007/s11010-014-2133-0.

[14] R. Jin, T. Yang, P. Piroozfar, B.G. Kang, D. Wanatowski, C.M. Hancock, L. Tang, Project-based pedagogy in interdisciplinary building design adopting BIM, Eng. Constr. Archit. Manag. 25 (2018) 1376-1397. doi:10.1108/ECAM-07-2017-0119.

[15] R. Fruchter, Dimensions of Teamwork Education, Int. J. Eng. Educ. 17 (2001) 426-430.

[16] M.A. Alder, Comparing Time And Accuracy of BIM to On-Screen Takeoff for a Quantity Takeoff of Conceptual Estimate, Brigham Young University, 2006.

[17] A.S. Denzer, K.E. Hedges, From CAD to BIM: Educational strategies for the coming paradigm shift, in: AEI 2008 Build. Integr. Solut., Denver, USA, 2008. 
[18] T.L. Nguyen, T.X. Nguyen, Application of BIM tools in technician training, a case of Ho Chi Minh city construction college, Vietnam, in: Lect. Notes Civ. Eng., 2020. doi:10.1007/978-981-15-0802-8_198.

[19] F. Peterson, T. Hartmann, R. Fruchter, M. Fischer, Teaching construction project management with BIM support: Experience and lessons learned, Autom. Constr. $20 \quad$ (2011) 115-125. doi:10.1016/j.autcon.2010.09.009.

[20] W. Barham, P. Meadati, J. Irizarry, Enhancing student learning in structures courses with building information modeling, Congr. Comput. Civ. Eng. Proc. (2011) 850-857. doi:10.1061/41182(416)105.

[21] A. Mokhtar, BIM as a pedagogical tool for teaching HVAC systems to architecture students, in: Archit. Eng. Inst. Conf., Tysons, Virginia, USA, 2019.

[22] S. Suwal, V. Singh, Assessing students' sentiments towards the use of a Building Information Modelling (BIM) learning platform in a construction project management course, Eur. J. Eng. Educ. 43 (2018) 492-506. doi:10.1080/03043797.2017.1287667.

[23] A. Sánchez, C. Gonzalez-Gaya, P. Zulueta, Z. Sampaio, Introduction of building information modeling in industrial engineering education: Students' perception, Appl. Sci. 9 (2019) 1-19. doi:10.3390/app9163287.

[24] ISO, ISO 19650 - Organization of information about construction works -- Information management using building information modelling, 2018.

[25] ISO, ISO 29481 - Building information models -- Information delivery manual, 2016.

[26] CORFO, PlanBIM, (2019).

[27] PlanBIM, BIM standard for public projects, Santiago de Chile, 2019.
[28] C. Briones Lazo, Brechas y desafíos para la educación BIM en Chile, (2019) 24.

[29] A. Ghosh, K. Parrish, A.D. Chasey, Implementing a Vertically Integrated BIM Curriculum in an Undergraduate Construction Management Program, Int. J. Constr. Educ. Res. 11 (2015) 121-139. doi:10.1080/15578771.2014.965396.

[30] M.G. McGee, Human spatial abilities: Sources of sex differences, Praeger Publishers Inc., New York, USA, 1979.

[31] S.A. Sorby, T. Drummer, K. Hungwe, P. Charlesworth, Developing 3-D spatial visualization skills for non-engineering students, in: ASEE Annu. Conf. Expo., 2005: pp. 4047-4057.

[32] S. Glick, D. Porter, C. Smith, Student Visualization: Using 3-D Models in Undergraduate Construction Management Education, Int. J. Constr. Educ. Res. 8 (2012) 26-46. doi:10.1080/15578771.2011.619247.

[33] C.B. Williams, J. Gero, Y. Lee, M. Paretti, Exploring spatial reasoning ability and design cognition in undergraduate engineering students, in: Proc. ASME Des. Eng. Tech. Conf., Montreal, Quebec, Canada, 2010: pp. 669-676. doi:10.1115/DETC201028925.

[34] S.A. Sorby, B.J. Baartmans, The Development and Assessment of a Course for Enhancing the 3-D Spatial Visualization Skills of, J. Eng. Educ. 89 (2000) 301-307.

[35] F.J.A. Alvarez, E.B.B. Parra, F. Montes Tubio, Improving graphic expression training with $3 \mathrm{D}$ models, J. Vis. (2017). doi:10.1007/s12650-017-04248.

[36] J. De La Torre Cantero, J.L. Saorín, C. Carbonell, M.D. Del Castillo Cossío, M. Contero, 3D Modeling as an educational tool for the development 
of skills of the new degrees in Arts, Arte, Individuo y Soc.

(2012).

doi:10.5209/rev_ARIS.2012.v24.n2.39025.

[37] N. Martín-Dorta, J.L. Saorín, M. Contero, Development of a fast remedial course to improve the spatial abilities of engineering students, J. Eng. Educ. 97 (2008) 505-513. doi:10.1002/j.21689830.2008.tb00996.x.

[38] R.M. Onyancha, M. Derov, B.L. Kinsey, Improvements in Spatial ability as a result of targeted training and computer-aided Design software use: analyses of object geometries and rotation types, J. Eng. Educ. 98 (2009) 157-167. doi:10.1002/j.21689830.2009.tb01014.x.
[39] R.T. Duesbury, H.F. O'Neil, Effect of type of practice in a computer-aided design environment in visualizing three-dimensional objects from twodimensional orthographic projections, J. Appl. Psychol. (1996). doi:10.1037/0021-9010.81.3.249.

[40] H.B.P. Gerson, S.A. Sorby, A. Wysocki, B.J. Baartmans, The Development and Assessment of Multimedia Software for Improving 3-D Spatial Visualization Skills, Comput. Appl. Eng. Educ. (2001). doi:10.1002/cae.1012. 